\title{
Actitud y su efecto en la exportación en las pequeñas y medianas empresas en Puerto Rico: estudio de multicasos
}

\author{
Maribel Ortiz Soto / mortiz126@suagm.edu \\ Escuela de Negocios y Empresarismo \\ Universidad del Turabo
}

Recibido: 14 de marzo de 2012

Aceptado: 11 de febrero de 2014

\section{RESUMEN:}

La mayor parte de las PYMES en Puerto Rico tienen un enfoque doméstico, lo que requiere que se analice los factores que influyen en el proceso de toma de decisión. El objetivo de este estudio es evaluar el efecto de la actitud hacia la exportación, el riesgo y la innovación de los dueños en el comportamiento (toma de decisión) hacia la exportación. El interés es comparar las PYMES que nunca han exportado, con las que exportan actualmente y con ex-exportadoras a través del uso del método del estudio de multicasos. El estudio reveló que la actitud hacia la exportación y la actitud hacia el riesgo son los factores que más influyen en el comportamiento hacia la exportación.

Palabras clave: PYMES, comportamiento, exportación y factores internos

\begin{abstract}
:
Most Puerto Rican SME's have a domestic focus, which may require an analysis of the factors that influence the decision- making process. The objective of this study is to evaluate the effect of the attitude of the entrepreneur/owner toward export business, risks, and innovation on the behavior (decision-making) toward exportation. The research intention is to compare the characteristics of the non-exporters, exporters, and former exporters by the use of multicase study. The study revealed that the attitudes toward export business and toward risks are the factors that most influence behavior toward export activity.
\end{abstract}

Keywords: SME's, behavior, export, internal factors 


\section{INTRODUCCIÓN}

En las últimas décadas ha habido un aumento significativo en los negocios internacionales. Debido a la importancia que tienen las pequeñas y medianas empresas (PYMES) en el crecimiento económico de un país y el desarrollo acelerado de la internacionalización, dichas empresas están considerando cada vez más la exportación como estrategia de entrada a los mercados extranjeros (Leonidou, 2004). La internacionalización no ha sido un proceso fácil. Según dicho investigador, existen factores internos y externos que impulsan a las empresas a decidir exportar.

Fillis (2002) y otros investigadores (Crick y Chaudhry, 1997; Halikias y Panayotopoulou, 2003; Ibeh, 2004; Suarez y Álamo, 2005) concuerdan en que los factores que en realidad impulsan a las empresas a moverse hacia la internacionalización son los factores internos, especialmente los relacionados a la actitud del dueño.

Puerto Rico no está ajeno a la realidad de la internacionalización. Diferentes empresas han probado que pueden competir en mercados internacionales. Sin embargo, la mayor parte de las PYMES del país mantienen un enfoque doméstico o local. Rodríguez (2004), Presidente de la Junta de Planificación para ese año, señala que se le ha prestado poca atención a este aspecto de la economía. Como resultado, la empresa local continúa con un enfoque doméstico y carece de una orientación hacia la exportación.

Aun cuando las empresas en Puerto Rico presentan una orientación más local, no existen estudios que expliquen las razones que propician esta tendencia. Existe un claro problema de falta de información para comprender y explicar el fenómeno relacionado específicamente a las actitudes del dueño empresario que facilitan o limitan el comportamiento de las PYMES de Puerto Rico a entrar a los mercados internacionales.

\section{Marco teórico}

El iniciar el proceso estratégico del establecimiento de negocios fuera de su mercado doméstico, requiere de una decisión de creci- 
miento. El crecimiento de una empresa depende tanto de factores externos como de factores internos, tales como la mentalidad del empresario/dueño, recursos económicos, conocimientos del recurso humano en las áreas de producción o servicio, orientación hacia el mercado e innovación, entre otros. Según O’Gorman (2001), lo que inicia el proceso de crecimiento en una empresa es la decisión y selección estratégica hecha por el dueño empresario. Leonidou (2004) y Suárez y Álamo (2005) confirman que el factor que impulsa o impide a las empresas a iniciar su proceso de internacionalización son los factores relacionados a la gerencia (actitud, percepción y características) y recursos (capacidad) de la empresa. Los investigadores mencionan que la percepción que se tiene sobre los factores internos y externos será tomada en consideración en el proceso de la toma de decisiones. Asimismo, coinciden que la dimensión del comportamiento del dueño que es crítica en el proceso de exportar, abarca las expectativas, las creencias y la actitud hacia la exportación.

La decisión de exportar o no exportar puede variar según la actitud que tenga la gerencia hacia este comportamiento. La base teórica utilizada para explicar la relación entre las actitudes y un comportamiento, en este caso decidir exportar, es la Teoría de Acción Razonada de Ajzen y Fishein (1980). El fin de la teoría es predecir y comprender la conducta individual, por lo que ha sido utilizada en diferentes estudios relacionados a la exportación (Jaffe y Pasternak, 1994; Patterson, Cicic y Shoham, 1997; McNeal, 2003, entre otros).

Esta teoría establece que la intención de realizar un acto o asumir un comportamiento (en este caso, decidir exportar o no exportar) es una función de la actitud que tiene el individuo hacia ese comportamiento. Expone que la intención de actuar (exportar o no exportar) depende de las creencias que tenga la persona de que ese comportamiento tendrá unos resultados, y la evaluación de esos resultados lo motivará a actuar o no actuar. Es decir, el comportamiento está determinado por la intención y la intención está determinada por la actitud que tenga el individuo hacia ese comportamiento. Uno de los aspectos más importantes en esta teoría es el relacionado a las "creencias" como antecedentes de las actitudes, pues plantea que la actitud hacia un objeto o situación es el producto de las creencias 
que la persona tiene hacia el mismo. De igual forma, postula que tales creencias contienen, por una parte, elementos de expectativa y, por otra, elementos de valor. La expectativa es la creencia de que la realización de cierta conducta dará lugar a determinados resultados. La deseabilidad de realizar esa conducta es el elemento de valor, el cual está representado por el grado en que la persona califica como positivos o negativos los resultados expresados en la creencia. Si el individuo cree que el comportamiento tendrá consecuencias positivas, asumirá una actitud positiva que llevará al comportamiento de actuar. $\mathrm{Si}$, por el contrario, el individuo tiene la creencia de que las consecuencias serán negativas, asumirá una actitud negativa y su comportamiento será desfavorable (preferirá no actuar).

Figura 1

Teoría de Acción Razonada de Ajzen y Fishnein (1980)

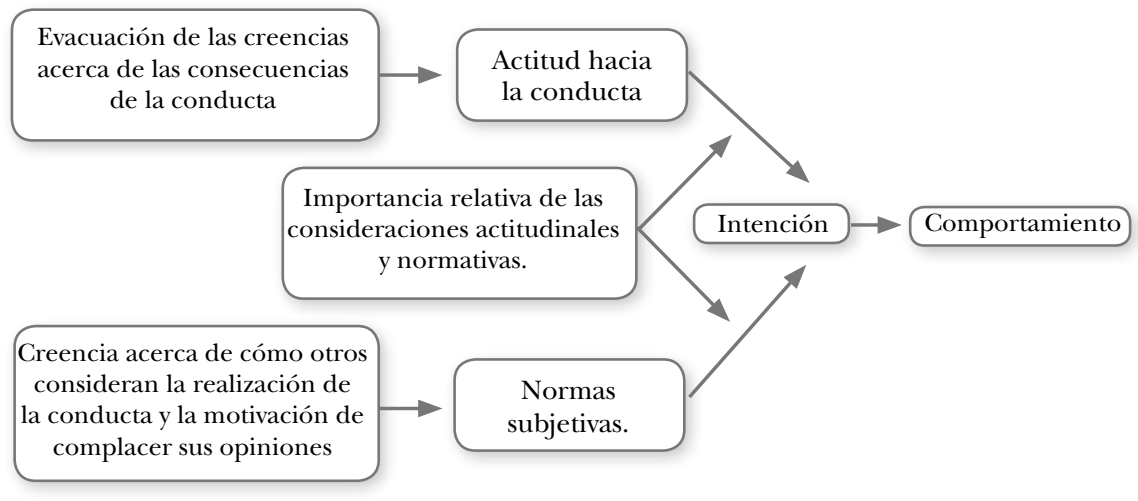

Fuente: Eiser, J. R. (1989). Psicología Social, Actitudes, Cognición y Conducta Social. Madrid: Ediciones Pirámide.

La Teoría de Acción Razonada permite explicar la actitud del dueño hacia la exportación y su decisión de poner en acción dicha estrategia. Según Jaffe y Pasternak (1994), lo que impulsa al empresario a decidir exportar o no exportar es la creencia que tenga este empresario de que su empresa cuenta o no cuenta con los recursos necesarios para realizar exitosamente la actividad. La decisión de exportar o no exportar puede variar según la actitud de la gerencia a asumir riesgos y su percepción con relación a los riesgos asociados con el proceso de internacionalización (Jaffe y Pasternak, 1994). 
Crick y Chaudhry (1997) y Fillis (2002) puntualizan que el factor interno que impulsa la internacionalización es la motivación. La motivación se basa, entonces, en que la persona que toma la decisión, debe estar convencida de que el tamaño de la empresa y el conocimiento sobre el proceso de internacionalización le permiten dar esos pasos. La falta de conocimiento genera grandes incertidumbres, sobre todo, porque hay unas áreas críticas que pueden ser complicadas, por lo que puede afectar la actitud hacia la exportación.

Por su parte, Suárez y Álamo (2005) mencionan que la actitud de la gerencia se relaciona con la aversión al riesgo, innovación y flexibilidad. La literatura ha asociado la decisión de exportar con la percepción que tienen los gerenciales o dueños. El comportamiento de la gerencia a exportar depende de las expectativas, creencias y actitudes hacia la exportación. La percepción de la gerencia que puede explicar la decisión de comenzar a exportar es la percepción que tenga sobre las ventajas o las barreras u obstáculos que puede tener la actividad de exportación (dificultades).

En el caso de las PYMES, dado a la heterogeneidad y su ambiente operacional, según Ruzzier, Hisrich y Antoncic (2006), puede haber dificultades objetivas en la identificación de los recursos críticos necesarios para la internacionalización. Según la pequeña empresa se va internacionalizando, la actitud hacia la internacionalización, puede ser diferente (Suárez y Álamo, 2005). Por consiguiente, la decisión de exportar, no exportar o dejar de exportar, dependerá de la percepción y experiencia que haya tenido el dueño empresario con la actividad de exportación.

\section{Modelo Conceptual}

De acuerdo con la literatura, el factor interno de la empresa que más afecta la decisión de exportar es la actitud del dueño o gerente. Este estudio examinó cómo las variables independientes-actitud gerencial medidas en término de actitud hacia la exportación, hacia la innovación y hacia el riesgo-pueden ser factores que facilitan o impiden el comportamiento a exportar. Es decir, cómo la actitud puede influenciar el que el empresario decida exportar, dejar de exportar o no interese exportar. 
Figura 2

Modelo conceptual

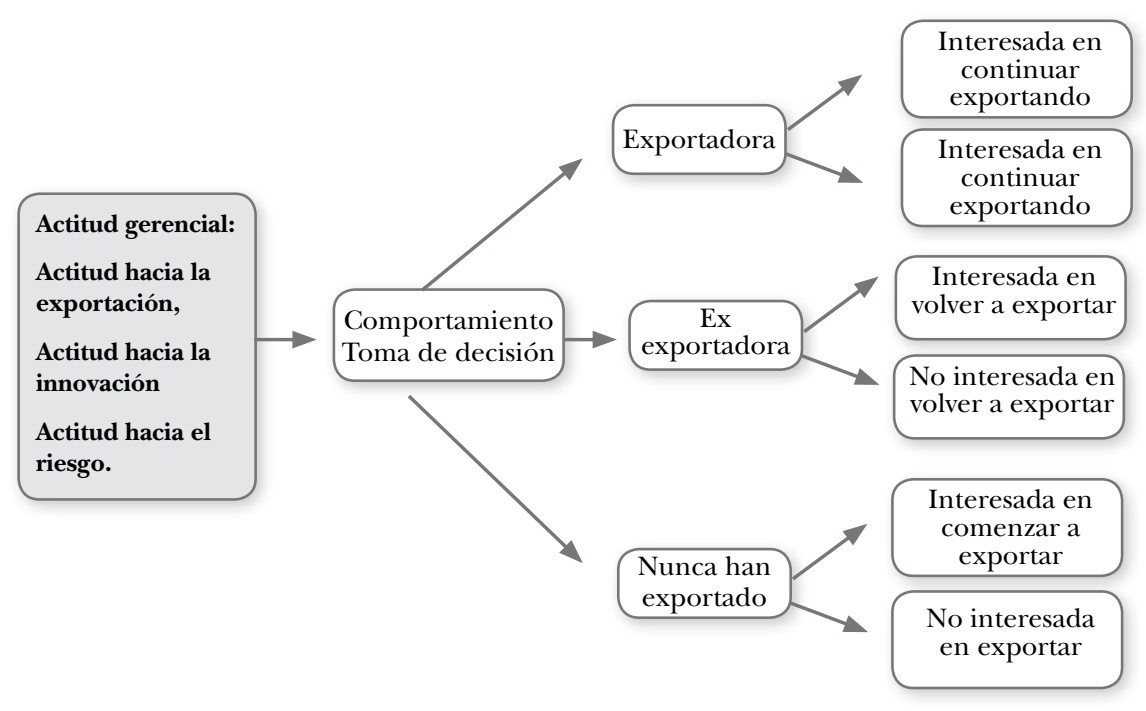

La Figura 2 presenta el marco conceptual gráfico del cual se derivan las siguientes preguntas de investigación:

1. De las PYMES a estudiar, ¿la actitud hacia la exportación, hacia el riesgo y hacia la innovación son factores que influyen comportamiento (en la toma de decisión) hacia la exportación?

2. De las actitudes a estudiar: actitud hacia la exportación, actitud hacia el riesgo y actitud hacia la innovación, ¿cuál o cuáles son la(s) que más influye(n) en el comportamiento hacia la exportación?

3. ¿Existen diferencias en las creencias, percepciones y experiencias relacionadas con la actitud hacia la exportación, hacia el riesgo y hacia la innovación entre los dueños de las empresas exportadoras con interés en exportar, de exportadoras sin interés en exportar, de empresas que nunca han exportado con interés en comenzar a exportar, de empresas que nunca han exportado sin interés en comenzar a exportar, de las ex-exportadoras con interés en volver a exportar y de las ex-exportadoras sin interés en volver a exportar que influyen en su comportamiento hacia la exportación? 


\section{Metodología}

Debido a la poca información que existe y a los pocos estudios realizados sobre el proceso de exportación en Puerto Rico, el enfoque de esta investigación fue de carácter exploratorio a través de un método cualitativo con estudio de caso. La estrategia de investigación utilizada fue la del multicasos, en el que se compararon seis pequeñas y medianas empresas de Puerto Rico. Según Huertas (2005), la ventaja que tiene este enfoque es que permite examinar los asuntos del proceso de exportación desde la perspectiva individual, concernientes a la actividad, por lo que se puede observar las múltiples maneras en que se manifiesta el proceso.

Yin (2004) menciona que cada caso debe ostentar un propósito determinado, por lo que la elección de los participantes no se realiza según los criterios muestrales estadísticos, sino por razones teóricas, en el que se logre identificar un conjunto de casos que sean representativos del fenómeno a analizar. Para la selección de las empresas participantes de los estudios de casos, se realizó un acercamiento a las distintas agencias que intervienen con las pequeñas y medianas empresas y exportación en Puerto Rico: Small Business Technology and Development Center (SBTDC) y Compañía de Comercio y Exportación. La selección fue a conveniencia, pero basada en parámetros claramente definidos en términos de nivel de experiencia con exportación. La muestra se compuso de pequeñas y medianas empresas, según la definición de la Agencia Federal de Pequeñas Empresa (Small Business Administration, SBA, 2008), cuyos dueños eran de diferentes sexos, sectores industriales y áreas de Puerto Rico. Dueños de empresas de PYMES multinacionales no fueron considerados, ya que cuentan con recursos que las pequeñas y medianas empresas independientes no tienen.

Con la ayuda de un representante de estas agencias, se logró identificar una empresa no exportadora sin interés en exportar, empresas no exportadoras interesadas en exportar, empresas que actualmente estaban exportando e interesadas en continuar exportando y empresas que habían dejado de exportar con interés en volver a exportar. A pesar de los esfuerzos realizados, no se pudo identificar 
una empresa exportadora sin interés en continuar exportando. Debido a esta situación, se identificó otra empresa no exportadora sin interés en comenzar a exportar, pero de un sector industrial diferente a la otra empresa entrevistada.

El instrumento de recolección de datos fue una Guía del Entrevistador, que incluye un conjunto de preguntas utilizadas para la discusión abierta de cada pregunta. Esto permite entrar en la discusión de detalles que un cuestionario estructurado no permitiría. El instrumento se dividió en cuatro partes: la primera parte permitió agrupar las empresas según su comportamiento con respecto a la exportación para luego poder obtener un perfil de cada grupo según sus características; la segunda parte evaluó las variables relacionadas a la actitud (hacia la exportación, hacia la innovación y hacia el riesgo); la tercera parte permitió medir los factores que, según la percepción del empresario participante, facilitan o dificultan el proceso de exportación; la cuarta y última parte del instrumento facilitó medir los factores relacionados a datos demográficos específicos y en rango para obtener la información relacionada a las características de la gerencia y de la empresa. De esta forma, el investigador confirmó la muestra representativa del estudio y pudo identificar los diferentes perfiles de cada grupo de empresas.

Para analizar los datos de los estudios de caso, se estableció un sistema estructurado de reporte con el propósito de manejar uniformemente los datos obtenidos. Para asegurar la validez de los datos, se abrió un expediente por cada entrevista que se realizó. Los expedientes se identificaron por el tipo de empresa que representaba el entrevistado. El nombre del dueño o empresario participante se obvió en todos los documentos; solo se escribió el tipo de empresa para garantizar el anonimato del participante. Se revisó individualmente la información obtenida por cada entrevistado. Luego que se transcribió independientemente cada estudio de caso, el investigador procedió a preparar una matriz donde se reorganizó la contestación de cada pregunta por cada tipo de empresa. Luego de preparar la matriz por categorías, se aplicó la técnica agregación categórica, recomendada por Stake (1995), donde se agrupan las unidades semejantes por sus atributos. Finalmente, se realizó un 
análisis cruzado de casos para comparar los hallazgos y llegar a conclusiones.

\section{Discusión DE LOS CASOS}

\section{CASO I: EMPRESA QUE NUNCA HA EXPORTADO CON INTERÉS EN EXPORTAR}

La empresa está ubicada en San Juan y se especializa en servicios de consultoría en Administración de Empresas. El dueño se encuentra entre las edades de 41-50 años, con un nivel educativo de bachillerato en Administración de Empresas. El dueño habla español e inglés. La empresa lleva dos años de operación y tiene dos empleados a tiempo completo y, según su necesidad, subcontrata personas. El tamaño de la empresa, de acuerdo a su ingreso anual, es de $\$ 200,000.00$.

En relación a la actitud hacia la exportación, el participante expone que él cree que la exportación ofrece grandes oportunidades de crecimiento porque es un mercado más grande que el de Puerto Rico, por lo que hay más posibilidades de obtener más ganancias por ser un servicio. El empresario aclara que este servicio no ha sido tan aceptado en Puerto Rico. Además explica que la experiencia negativa que ha tenido con el mercado local y debido a conversaciones informales que ha tenido con empresas extrajeras latinoamericanas, piensa que exportar es una decisión sabia y considera que la rentabilidad financiera de su empresa puede ser mayor si se concentra en el mercado extranjero. Este análisis de los posibles resultados hace que asuma un comportamiento de interés en exportar.

$\mathrm{Al}$ discutir sobre el aspecto relacionado al riesgo, el empresario menciona que exportar tiene riesgos, pero que los mismos no son significativos. Además, expresa que siempre hay unos riesgos, pero cree que quizás en el caso de este tipo de servicio los riesgos pueden ser menores, porque la inversión económica es menor. Uno de los riesgos que se puede encontrar en algunos de los países es que no se respeten los derechos de autor. Sin embargo, al analizar los riesgos que cree que la empresa puede enfrentar en el mercado internacional, el participante considera que son mínimos, por lo que vale la pena arriesgarse.

ISSN 1541-8561 | 61 
$\mathrm{Al}$ dialogar sobre tema de la actitud hacia las innovaciones, el entrevistado menciona que el cliente de hoy requiere de innovaciones constantes. El participante parte de la creencia de que la empresa interesa obtener resultados y se requiere de la innovación para lograr esos resultados. Por el producto ser un servicio, el entrevistado cree que la innovación es más viable y constante, ya que se ajustará de acuerdo a las necesidades de la empresa y del país.

\section{Caso II: Empresa que nunca ha exportado y no que tiene interés en eX- PORTAR A CORTO PLAZO (SÍ EN UN FUTURO)}

La empresa está ubicada en el área sur de Puerto Rico, en Ponce, y es una empresa procesadora de café. El dueño/empresario se encuentra entre las edades de 31-40 años, con un nivel educativo de maestría en Administración de Empresas y habla español e inglés. La empresa lleva dos años de operación y tiene de seis empleados a tiempo completo. El tamaño de la empresa, de acuerdo a su ingreso anual, es de $\$ 200,000.00$.

El entrevistado manifiesta que la exportación ofrece beneficios, por eso es que considera exportar en algún momento en el futuro. El participante cree que la exportación puede aumentar las ganancias de su empresa, pero esto es si maneja bien los riesgos relacionados a los costos que envuelve, en su caso, la exportación del café. $\mathrm{Al}$ analizar los resultados que puede tener la exportación, el empresario considera que el mercado extranjero puede tener mayor rentabilidad que el de Puerto Rico, ya que puede ser mucho mayor, por lo que podría vender mayor cantidad de café en el extranjero. Sin embargo, cuando el entrevistado analiza los resultados desde el punto de vista de los costos, aclara que exportar café tiene grandes costos (bróker, seguros, transportación, etc.), mucha competencia y es más complicado que venderlo a nivel local. Debido a los recursos limitados de la empresa al momento, el empresario cree que no sería tan rentable exportar el producto a corto plazo.

$\mathrm{Al}$ discutir el tema del riesgo, el participante comenta que todas las decisiones se miden a base de las consecuencias y resultados; esas consecuencias pueden envolver riesgos. El empresario expone que, en el caso de un producto como el café, hay constantes riesgos por 
ser un producto perecedero. Además, señala mayores riesgos, desde ambientales causados por huracanes, hasta económicos por los costos y seguros. Por ser una empresa pequeña, tiene recursos limitados, por lo que el empresario entiende que actualmente no puede manejar los riesgos que envuelve la actividad de exportación.

Al dialogar sobre las innovaciones, el dueño comenta que el café tiene mucha competencia en las diferentes categorías existentes, por lo que se tiene que ser creativo e innovador en varios aspectos del negocio. El empresario cree que con las innovaciones puede lograr una ventaja competitiva.

\section{CASO III: EMPRESA QUE NUNCA HA EXPORTADO Y SIN INTERÉS EN EXPORTAR}

La empresa está ubicada en el centro-este de Puerto Rico, en Caguas, y es una distribuidora de cartón. La dueña se encuentra entre las edades de 31-40 años, con un nivel educativo de bachillerato en Administración de Empresas. La dueña habla español, inglés y portugués. La empresa lleva ocho años de operación y tiene dieciocho empleados a tiempo completo. El tamaño de la empresa, de acuerdo a su ingreso anual, es de $\$ 4,000,000.00$.

Al discutir el tema de la actitud hacia la exportación, la participante comenta que nunca antes la había considerado. Por tal razón, no tiene ninguna actitud. Tiene desconocimiento de cuánto beneficio puede obtener a través de la exportación y expresa que no cree

que en estos momentos exportar sea una decisión sabia, pues piensa que la misma no le ofrece oportunidades de crecimiento, por lo que prefiere no hacerlo.

En relación a la variable sobre la actitud hacia el riesgo, la entrevistada expone que en la vida hay que tomar riesgos, pero que estos tienen que haber sido analizados. Por eso, considera que hay que analizar la exportación para saber si es costo efectiva para su empresa. La empresaria cree que la exportación requiere de recursos económicos, así como de mayor personal y maquinaria, resultando en mayores riesgos. Piensa que este panorama dificulta bastante el tomar la decisión de exportar porque al no conocer lo que envuelve el proceso, cree que puede conllevar altos riesgos. 
$\mathrm{Al}$ dialogar sobre la innovación, reconoce que las innovaciones son importantes. Sin embargo, el innovar puede requerir de presupuesto y ellos tendrían que evaluar cuán costo-efectivo sería esa innovación. Para decidir innovar, tienen que tener una seguridad de que el producto se va a vender y de que los cambios van a rendir ganancias a la empresa. En los últimos cuatro años, no han desarrollados nuevos productos.

\section{CASO IV: EMPRESA EXPORTADORA CON INTERÉS EN CONTINUAR EXPORTANDO}

La empresa está ubicada en el este de Puerto Rico, en Fajardo, y es una manufacturera de alimento (pique). El dueño empresario se encuentra entre las edades de $50+$, con un nivel educativo de bachillerato en Administración de Empresas. El dueño habla español, inglés y francés. La empresa lleva cuatro años de operación y en el último año y medio ha exportado. Tiene tres empleados a tiempo completo y el tamaño de la empresa, de acuerdo a su ingreso anual, es de $\$ 100,000.00$.

El empresario entrevistado comenta que en su experiencia, la exportación siempre le ha rendido frutos y le ha dado beneficios porque el mercado fuera de Puerto Rico es más grande que el local. Siempre le ha rendido ganancias; si no fuera así, no hubiese considerado exportar. El dueño está totalmente convencido de que exportar es una decisión sabia.

$\mathrm{Al}$ discutir el tema del riesgo, el dueño expresa que en la vida hay que tomar riesgos, si no se toman riesgos, no se logra nada. El empresario cree que todo negocio tiene riesgos, pero estos deben ser calculados, analizados. Además, piensa que su empresa actualmente puede manejar los riesgos que envuelven la exportación y cuenta con todos los seguros para garantizar minimizar los mismos.

En relación a las innovaciones, para el empresario son importantes. El entrevistado entiende que hay que ser creativo y buscar crear productos de acuerdo a lo que quieren los clientes. Comenzaron con tres productos y actualmente tienen cinco productos. Además, han tenido que mudarse para ampliar la producción. La innovación les ha dado resultados positivos que los han motivado a continuar exportando. 


\section{CASO V: EMPRESA EX-EXPORTADORA CON INTERÉS EN VOLVER A EXPORTAR}

La empresa está ubicada en el norte de Puerto Rico, en Toa Vaja, y es una manufactura de alimento (mojito). La dueña se encuentra entre las edades de 50+, con un nivel educativo de grado asociado y habla español e inglés. Ha visitado más de cinco países. La empresa lleva siete años de operación y a los cinco comenzó a exportar por primera vez. Por problemas de precio y desconocimiento del mercado, tuvo que dejar de exportar y, desde entonces, está buscando la forma de volver a hacerlo. Tiene cuatro empleados a tiempo completo. El tamaño de la empresa, de acuerdo a su ingreso anual, es de $\$ 400,000.00$.

La empresaria entrevistada cree que la exportación ofrece grandes beneficios, aunque no ha logrado mantenerse exportando. Aclara que la empresa no es la que tiene que asumir los costos de transportación y seguro, sino el cliente que le compra para revender. Esta situación le puede permitir ganancias a la empresa. Sin embargo, estos costos en que tiene que incurrir el cliente hacen que aumente el precio al cual este intermediario lo ofrecerá al consumidor final, lo que evita que el precio sea competitivo. Añade que, si se logra manejar estos costos, los resultados pueden ser muy buenos.

$\mathrm{Al}$ discutir el tema del riesgo, la dueña expresa que en la vida hay que tomar riesgos y que ella no tiene problema con asumirlos, pero estos tienen que ser evaluados. La participante considera que la empresa tiene que estar bien sólida en el mercado local para después lanzarse al mercado extranjero, de forma tal que la empresa pueda absorber los riesgos que puedan surgir por la exportación.

En el caso de la exportación, expresa que los riesgos en la industria de alimentos pueden ser altos porque, aunque se puede lograr vender el producto, los alimentos requieren de cierto manejo y costos. Si bien el cliente es el que asume los riesgos de suceder algo, este puede decidir no continuar comprando y, dependiendo de la negociación original que se realizó, el resto de la mercancía se puede quedar y hasta perder. Aun así, actualmente, la empresa puede manejar los riesgos que envuelve la exportación y por eso es que está interesada en volver a exportar. 
En relación a las innovaciones, la participante menciona que las innovaciones son importantes. La empresa comenzó con dos productos y actualmente tiene seis productos. La empresaria cree que las empresas deben mantenerse innovando. Puntualiza que estaría dispuesta a innovar (cambiar o adaptar) el producto sin ningún problema, si se identifica que el mercado necesita un nuevo producto o si identifica una nueva oportunidad para un producto en otro lugar.

\section{CASO VI: EMPRESA EX-EXPORTADORA SIN INTERÉS EN VOLVER A EXPORTAR}

La empresa está ubicada en el área Metropolitana de Puerto Rico, en San Juan, y es una empresa de servicio: una agencia de publicidad. El dueño/empresario se encuentra entre las edades de $50+$, con un nivel educativo de bachillerato en Artes y habla español e inglés. Ha visitado 2 países. La empresa lleva catorce años de operación. En el noveno año, surgió la oportunidad de exportar su servicio, pero la experiencia fue negativa, por lo que no continuó exportando. Tiene más de quince empleados a tiempo completo. El tamaño de la empresa, de acuerdo a su ingreso anual, es de sobre $\$ 300,000.00$.

Al dialogar sobre el tema de la actitud sobre la exportación, el entrevistado entiende que la exportación le ha rendido ciertos beneficios. Expresa que obtuvo alguna ganancia y un aumento de volumen momentáneo, pero no fue permanente. Cree que la rentabilidad a través de la exportación puede aumentar en unos aspectos, pero en otros momentos puede no ser tan rentable, ya que depende del país donde se vaya a ofrecer el producto. El empresario comenta que en la industria de la publicidad, según su experiencia, el mercado local es mucho más rentable que el mercado extranjero. Un factor importante que el entrevistado destaca es el intercambio de moneda en el extranjero, pues hay que analizar cómo afecta al precio, costos e ingresos.

Respecto al riesgo, el entrevistado aclara que en la vida hay que tomar riesgos, pero estos deben ser calculados en la medida que se adquiere conocimiento. Factores tales como la moneda, los impuestos y las leyes, pueden representar riesgos significativos. El participante indica que la industria de las agencias o consultoría tiene 
que financiar al cliente en el país extranjero, por lo que tiene que asumir un gran riesgo. Al evaluar si la empresa puede manejar los riesgos que envuelve la exportación, el empresario aclara que en estos momentos no está exportando, pero si la empresa decidiera exportar, el evaluar y planificar la estrategia, sería parte del manejo de ese riesgo.

En relación al tema de las innovaciones, según el dueño, las mismas son importantes para la empresa. El entrevistado cree que todas las empresas dedicadas al servicio, en alguna medida, tienen que ser creativas, especialmente las dedicadas a la publicidad, al mercadeo y a la investigación. En el caso de la publicidad, la creatividad es parte de esa innovación y se desarrollan servicios, según la solicitud del cliente. La empresa está constantemente en un proceso de innovación para ajustarse a las necesidades del cliente.

\section{Discusión de RESULTADOS}

$\mathrm{Al}$ evaluar los casos, los datos relacionados a la actitud sobre la exportación reflejaron que la mayor parte de las empresas reconocen que la exportación es beneficiosa y es más rentable que el mercado local, debido a que el mercado extranjero es más grande que el mercado local. Para la empresa no exportadora con interés en exportar a corto plazo, así como para la empresa no exportadora con interés en exportar a largo plazo, el creer que la exportación le ofrecerá resultados positivos demuestra su actitud positiva hacia la exportación, por lo que están motivadas a exportar. Por otro lado, para la empresa exportadora y para la ex-exportadora con interés en volver a exportar la experiencia es lo que evidencia resultados positivos, por lo que su actitud hacia la exportación también es positiva y su comportamiento favorece la exportación.

Los resultados de la empresa ex-exportadora sin interés en volver a exportar no fueron los esperados. Su experiencia negativa afecta su actitud hacia la exportación de forma negativa, lo que lo impulsa al comportamiento de no querer a volver a exportar. Al no tener suficiente conocimiento, ni experiencia en la actividad de exportación, la empresa no exportadora sin interés en comenzar a exportar parte 
de la creencia de que la exportación no le ofrecerá resultados positivos, entendiendo que el mercado local le ofrece mejores beneficios en todos los aspectos. A tal efecto, su actitud hacia la exportación es negativa, lo que motiva el comportamiento de no querer exportar.

En relación a la actitud hacia el riesgo, todos coincidieron en que la exportación tiene riesgos. Sin embargo, algunas de las empresas tiene recursos para manejar los riesgos (exportadora con interés en continuar exportando y ex-exportadoras con interés en volver a exportar) y otras (como las dos que nunca han exportado con interés en exportar y ex-exportadora sin interés en volver a exportar) entienden que tienen recursos limitados, por lo que creen que no pueden manejar los riesgos que envuelve la exportación. Su percepción sobre los riesgos que envuelve la exportación es negativa; creen que los resultados serán negativos (no hay elemento de valor), por lo que su actitud sobre la exportación es negativa. Esto induce al comportamiento de no interesar comenzar o volver a exportar.

Las empresas relacionadas al servicio tuvieron opiniones diferentes. La empresa no exportadora con interés en exportar de la industria de servicio entiende que los riesgos relacionados a la exportación son mínimos por ser un producto intangible. Sin embargo, la empresa ex-exportadora, sin interés en volver a exportar, entiende que aun cuando su producto es un servicio, existen altos riesgos relacionados a la exportación por su tipo de industria.

En la variable relacionada a la actitud hacia la innovación, los resultados reflejaron que todas las empresas están de acuerdo en que las innovaciones son importantes, por lo que la actitud hacia la innovación es positiva. La mayoría está de acuerdo en hacer modificaciones a sus productos y hacer cambios para lograr exportar el producto. Sin embargo, la empresa no exportadora sin interés absoluto de exportar fue la única empresa que tuvo sus reservas para modificar el producto. Al observar la Tabla 1 sobre el resumen de los datos por variable, se puede notar que del tamaño de la empresa, su antigüedad o sus ingresos, no parecen ser factores que influyen en la actitud sobre la exportación, innovación o riesgo. 
Tabla 1

\begin{tabular}{|c|c|c|c|c|c|c|}
\hline $\begin{array}{l}\text { Característica } \\
\text { del empresario }\end{array}$ & $\begin{array}{l}\text { C I: Empresa } \\
\text { que nunca } \\
\text { ha exportado } \\
\text { con interés en } \\
\text { comenzar a } \\
\text { exportar }\end{array}$ & $\begin{array}{l}\text { C II: Empresa } \\
\text { que nunca } \\
\text { ha exportado } \\
\text { sin interés en } \\
\text { comenzar a } \\
\text { exportar (Sí en } \\
\text { el futuro) }\end{array}$ & $\begin{array}{l}\text { C III: Empresa } \\
\text { que nunca } \\
\text { ha exportado } \\
\text { sin interés en } \\
\text { comenzar a } \\
\text { exportar (No } \\
\text { en el futuro) }\end{array}$ & $\begin{array}{l}\text { C IV: Empresa } \\
\text { exportadora } \\
\text { con interés } \\
\text { en continuar } \\
\text { exportando }\end{array}$ & $\begin{array}{l}\text { C V: Empresa } \\
\text { ex exportadora } \\
\text { con interés } \\
\text { en continuar } \\
\text { exportando }\end{array}$ & $\begin{array}{l}\text { C V: Empresa } \\
\text { ex } \\
\text { exportadora } \\
\text { sin interés } \\
\text { en continuar } \\
\text { exportando }\end{array}$ \\
\hline $\begin{array}{l}\text { Tipo de } \\
\text { empresa }\end{array}$ & $\begin{array}{l}\text { Servicios en } \\
\text { consultoría en } \\
\text { Administración } \\
\text { de Empresa }\end{array}$ & $\begin{array}{l}\text { Manufacturera, } \\
\text { Procesadora } \\
\text { de Café }\end{array}$ & Distribuidora & $\begin{array}{l}\text { Manufacturera, } \\
\text { de alimento }\end{array}$ & $\begin{array}{l}\text { Manufacturera, } \\
\text { de alimento }\end{array}$ & $\begin{array}{l}\text { Servicio; } \\
\text { Agencia de } \\
\text { publicidad }\end{array}$ \\
\hline Género & Masculino & Masculino & Femenina & Masculino & Femenina & Masculino \\
\hline Edad & 41-50 años & $31-40$ & $31-40$ & $50+$ & $50+$ & $50+$ \\
\hline $\begin{array}{l}\text { Nivel } \\
\text { educativo }\end{array}$ & $\begin{array}{l}\text { Bachillerato en } \\
\text { Administración } \\
\text { de Empresas }\end{array}$ & $\begin{array}{l}\text { Maestría en } \\
\text { Administración } \\
\text { de Empresas }\end{array}$ & $\begin{array}{l}\text { Bachillerato en } \\
\text { Administración } \\
\text { de Empresas }\end{array}$ & $\begin{array}{l}\text { Bachillerato en } \\
\text { Administración } \\
\text { de Empresas }\end{array}$ & $\begin{array}{l}\text { Grado } \\
\text { Asociado }\end{array}$ & $\begin{array}{l}\text { Bachillerato } \\
\text { en Artes }\end{array}$ \\
\hline $\begin{array}{l}\text { Idiomas } \\
\text { que habla }\end{array}$ & $\begin{array}{l}\text { Español } \\
\text { e inglés }\end{array}$ & $\begin{array}{l}\text { Español } \\
\text { e inglés }\end{array}$ & $\begin{array}{l}\text { Español, inglés } \\
\text { y portugués }\end{array}$ & $\begin{array}{l}\text { Español, inglés } \\
\text { y francés }\end{array}$ & $\begin{array}{l}\text { Grado Español } \\
\text { e inglés }\end{array}$ & $\begin{array}{l}\text { Español } \\
\text { e inglés }\end{array}$ \\
\hline $\begin{array}{l}\text { Años de } \\
\text { operación }\end{array}$ & 2 años & 2 años & 8 años & 4 años & 7 años & 14 años \\
\hline $\begin{array}{l}\text { Cantidad de } \\
\text { empleados }\end{array}$ & 2 & 6 & 18 & 3 & 4 & 15 \\
\hline Ingreso anual & $\$ 200,000.00$ & $\$ 100,000.00$ & $\$ 4,000,000.00$ & $\$ 100,000.00$ & $\$ 400,000.00$ & $\$ 300,000.00$ \\
\hline $\begin{array}{l}\text { Actitud hacia } \\
\text { exportación }\end{array}$ & Positiva & $\begin{array}{l}\text { Positiva, si se } \\
\text { manejan los } \\
\text { riesgos }\end{array}$ & $\begin{array}{l}\text { Negativa, } \\
\text { no tiene } \\
\text { conocimiento } \\
\text { sobre } \\
\text { exportación }\end{array}$ & Muy positiva & $\begin{array}{l}\text { Positiva, } \\
\text { calculada }\end{array}$ & Negativa \\
\hline $\begin{array}{l}\text { Actitud hacia } \\
\text { innovación }\end{array}$ & Positiva & Positiva & $\begin{array}{l}\text { Negativa, } \\
\text { requiere } \\
\text { de altas } \\
\text { inversiones }\end{array}$ & Positiva & Positiva & Positiva \\
\hline $\begin{array}{l}\text { Actitud hacia } \\
\text { el riesgo }\end{array}$ & $\begin{array}{l}\text { Positiva, pero } \\
\text { calculado }\end{array}$ & $\begin{array}{l}\text { Positiva, pero } \\
\text { calculado }\end{array}$ & $\begin{array}{l}\text { Positiva, pero } \\
\text { sumamente } \\
\text { calculado }\end{array}$ & $\begin{array}{l}\text { Positiva } \\
\text { Calculada }\end{array}$ & $\begin{array}{l}\text { Positiva } \\
\text { Calculada }\end{array}$ & $\begin{array}{l}\text { Positiva, pero } \\
\text { sumamente } \\
\text { calculado }\end{array}$ \\
\hline
\end{tabular}

\section{Conclusiones}

Esta investigación tuvo como objetivo entender si la actitud hacia la exportación, hacia el riesgo y hacia la innovación afecta a las PYMES puertorriqueñas en su comportamiento relacionado a la exportación. El estudio concuerda con lo postulado en la literatura: la actitud de la gerencia tiene una gran influencia en la decisión relacionada a la exportación (Ajzen \& Fishein, 1980; Jaffe \& Pasternak, 1994; McNeal, 2003; Patterson, Cicic \& Shoham, 1997). Los resultados del estudio sugieren que la variable actitud hacia la exportación 
es importante tanto para desarrollar el interés en exportar como para tomar la decisión de comenzar y continuar exportando. Cullen y Parboteeah (2005) exponen que la gerencia que carece de conocimiento y experiencia del ambiente internacional tiene una actitud negativa ante la posibilidad de experimentar en mercados extranjeros. Este postulado ayuda a entender por qué las empresas que nunca han exportado sin interés en comenzar a exportar (como la distribuidora de cartón) tienen una actitud pobre hacia la exportación. Estos empresarios tienen menos conocimiento sobre el proceso de exportación, por lo no están claros de qué pueden esperar de esta actividad y, por consiguiente, no identifican un elemento de valor. Es de esperarse que tengan una actitud menos positiva hacia la exportación y su comportamiento sea demostrar menos interés en comenzar a exportar.

Este estudio sugiere que el conocimiento y la experiencia que tenga el empresario sobre el ambiente internacional pueden influenciar la actitud hacia la exportación. Por tanto, coincide con la Teoría de Acción Razonada de Ajzen y Fishbein (1980). Los empresarios con experiencias positivas y con mayor conocimiento tienden a crear expectativas positivas con elementos de valor, desarrollando una actitud más positiva hacia la exportación. La misma se traduce en la intención de continuar, comenzar o volver a exportar, impulsando a que se lleve a la acción el comportamiento. Por el contrario, las experiencias negativas influyen en el desarrollo de una actitud negativa que obstaculiza la intención de llevar a la acción la actividad de exportación. Por otro lado, el estudio permite inferir que el poco conocimiento o la ausencia de conocimiento que tienen las empresas no les permite evaluar posibles resultados. Esta incertidumbre los puede llevar a la creencia de que la exportación tiene grandes riesgos y pocos beneficios, lo que propicia una actitud negativa y limita el comportamiento hacia esta actividad. La variable riesgo resultó ser uno de los factores más considerados por las PYMES para decidir exportar, independientemente del tipo de empresa. No obstante, la interpretación sobre el riesgo puede variar según el sector industrial.

El estudio sugiere que existe una relación entre el riesgo percibido y la actitud hacia la exportación. La actitud hacia el riesgo y hacia 
la exportación resultaron ser las variables que más influyen en el comportamiento hacia la exportación. Por el contrario, la variable actitud hacia la innovación no sugiere ser tan significativa como las otras dos variables.

Los resultados de los estudios de casos expuestos permiten concluir que el conocimiento, la percepción y la experiencia que tenga el dueño empresario sobre la exportación influyen en la evaluación de los resultados que este piensa obtendrá si llevan a la acción la actividad de exportar y serán factores que influirán en la actitud, aumentando o disminuyendo la probabilidad hacia el comportamiento de comenzar, continuar o volver a exportar. Este resultado concuerda con Suárez y Álamo (2005), quienes aclaran que existen empresas con diferentes comportamientos, relacionados a la exportación y todas perciben y experimentan la actividad de exportación desde diferentes perspectivas.

\section{Contribución Del estudio}

El interés de esta investigación es que los hallazgos se divulguen en las distintas universidades que ofrezcan la concentración en Administración de Empresas o Negocios Internacionales, en el sector industrial y en las distintas dependencias del gobierno, para que cada una de estas organizaciones logre entender la importancia de la actitud en las PYMES y cómo afecta su proceso de internacionalización. Por otro lado, se espera que el estudio permita entender, desde la perspectiva de la actitud del dueño/gerente, las razones por las cuales algunas PYMES no están interesadas o quieren dejar de exportar. Al tomar como base esta información, las agencias y organizaciones pueden segmentar las empresas, como fue considerado en este estudio, de acuerdo a su perfil, para desarrollar estrategias específicas que ayuden a mejorar la actitud hacia la internacionalización. Dichos planes y programas podrían ayudar, a largo plazo, al desarrollo del empresarismo en Puerto Rico. El estudio, además, puede servir como base para la realización de otras investigaciones que permitan entender otros aspectos de las pequeñas y medianas empresas puertorriqueñas. 


\section{References}

Ajzen, I. \& Fishbein, M. (1980). Understanding attitudes and predicting social behavior. Englewood, Cliff: Prentice-Hall.

Crick, D. \& Chaudhry, S. (1997). Small businesses' motives for exporting: The effect of internationalization. Journal of Marketing Practice: Applied Marketing Science, 3(3), 156-170.

Cullen, J. \& Parboteeah, P. K. (2005). Multinational management: A strategic approach ( $3^{\text {rd }}$ edition). Mason, Ohio: South Western.

Eiser, J. R. (1989). Psicología social, actitudes, cognición y conducta social. Madrid: Ediciones Pirámide.

Fillis, I. (2002). Barriers to internationalization, an investigation of the craft microenterprise. European Journal of Marketing, 36(7/8), 912-927.

Halikias, J. \& Panayotopoulou, L. (2003). Chief executive personality and exporting volume. Management Decision, 41(4), 340-349.

Huerta, J. (2005). Guía para los estudios de caso como técnica de evaluación o investigación. Recuperado de academic.uprm.edu/jhuerta/HTMLobj-116/Estudio_de_caso.pdf

Ibeh, K. I. (2004). Furthering export participation in less performing developing countries: The effects of entrepreneurial orientation and managerial capacity factors. International Journal of Social Economic, 31(1/2), 94-110.

Jaffe, E. D. \& Pasternak, H. (1994). An attitudinal model to determine the export intention of non-exporting, small manufacturers. International Marketing Review, 11(3), 17-32.

Leonidou, L. C. (2004). An analysis of the barriers hindering small business export development. Journal of Small Business Management, 42(3), 279-302.

McNeal, R. (2003). Silent barrier: A study of prejudice toward foreigners as a barrier to exporting export feasibility by small and medium firms (Disertación doctoral). NovaSoutheastern University, Florida, U.S.

O'Gorman, C. (2001). The sustainability of growth in small-and medium-sized enterprises International. Journal of Entrepreneurial Behavior E̊ Research, 7(2), 60-75. 
Patterson, P. G., Cicic, M., \& Shoham, A. (1997). A temporal sequence model of satisfaction and export intentions of service firms. Journal of Global Marketing, 10(4): 2343.

Rodríguez, A. D. (2004). Comprehensive Economic Development Strategy (CEDS) Annual Report 2003-2004. Junta de Planificación de Puerto Rico. Recuperado de http://jp.pr.gov/Portal_JP/Portals/0/CEDS/CEDS2004INTERNET0.pdf

Ruzzier, M. A., Hisrich, R. D., \& Antoncic, B. (2006). SME Internationalization research: Past, present, and future. Journal of Small Business and Enterprise Development, 13(4), 476-497.

Small Business Administration (SBA). (2008). Frequently asked questions. Advocacy: the voice of small business in government. Office of Advocacy. Recuperado de http://www.sba.gov/advo

Stake, R. (1995). The art of case research. Thousand Oaks, CA: Sage Publications.

Suárez Ortega, S. M. \& Alamo Vera, F. R. (2005). SMES' internationalization: firms and managerial factors. International Journal of Entrepreneurial Behavior E Research, 11(4), 258 - 279.

Yin, R. K. (2004). Applications of case study research. Thousand Oaks, CA: Sage Publications. 